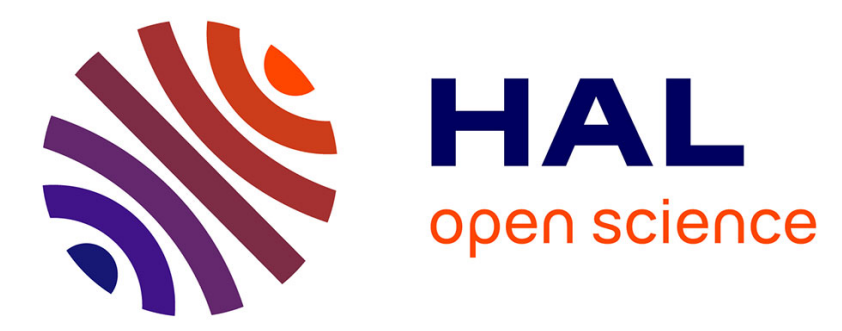

\title{
Accurate estimations of sea-ice thickness and elastic properties from seismic noise recorded with a minimal number of geophones: from thin landfast ice to thick pack ice
}

Ludovic Moreau, Jérôme Weiss, David Marsan

\section{To cite this version:}

Ludovic Moreau, Jérôme Weiss, David Marsan. Accurate estimations of sea-ice thickness and elastic properties from seismic noise recorded with a minimal number of geophones: from thin landfast ice to thick pack ice. Journal of Geophysical Research. Oceans, 2020, 10.1029/2020JC016492 . hal02986579

\section{HAL Id: hal-02986579 \\ https://hal.science/hal-02986579}

Submitted on 3 Nov 2020

HAL is a multi-disciplinary open access archive for the deposit and dissemination of scientific research documents, whether they are published or not. The documents may come from teaching and research institutions in France or abroad, or from public or private research centers.
L'archive ouverte pluridisciplinaire HAL, est destinée au dépôt et à la diffusion de documents scientifiques de niveau recherche, publiés ou non, émanant des établissements d'enseignement et de recherche français ou étrangers, des laboratoires publics ou privés. 


\title{
Accurate estimations of sea-ice thickness and elastic properties from seismic noise recorded with a minimal number of geophones: from thin landfast ice to thick pack ice
}

\author{
Ludovic Moreau $^{1}$, Jérôme Weiss ${ }^{1}$, David Marsan ${ }^{2}$ \\ ${ }^{1}$ Institut des Sciences de la Terre, UMR CNRS 5275, Université Grenoble Alpes, Grenoble, France \\ ${ }^{2}$ Institut des Sciences de la Terre, UMR CNRS 5275, Université de Savoie, Le Bourget du Lac, France
}

Key Points:

- The Young's modulus and Poisson's ratio of sea ice are estimated from seismic noise interferometry

- Bayesian inference is applied to icequake recordings for a simultaneous inversion of the icequake position and sea ice thickness

- In comparison with our previous work, where about 50 sensors were required, the number of stations is reduced by one order of magnitude

Corresponding author: Ludovic Moreau, ludovic.moreau@univ-grenoble-alpes.fr 


\begin{abstract}
Despite their high potential for accurate sea ice properties estimation, seismic methods are still limited by the difficulty of access and the challenging logistics of polar environments. Conventional seismic methods generally require tens of geophones together with active seismic sources for monitoring applications. While this is not an issue for mainland environment, it is restrictive for sea ice and prevents long-term monitoring. We introduce a method to estimate sea ice thickness and elastic properties from passive recordings of the ambient seismic field with a minimal number of geophones. In comparison with our previous work (Moreau et al, 2020), where about 50 sensors were used, the number of geophones is reduced by one order of magnitude, thanks to a new strategy of inversion of the passive seismic data. The method combines noise interferometry for estimating the elastic properties, with a Bayesian inversion of the dispersion in the waveforms of icequakes for inferring ice thickness, based on passive recordings from only 3 to 5 geophones, depending on the signal to noise ratio. We demonstrate its potential both on data recorded on thin landfast ice in Svalbard, and on data recorded on thick pack ice in the Arctic ocean.
\end{abstract}

\title{
Plain Language Summary
}

Seismic methods have high potential for monitoring important properties of sea ice, such as its thickness of rigidity. Such data are essential for improving climate models. However, the use of seismic methods is limited by the difficulty of access and the challenging logistics of polar environments. It is therefore essential to reduce as much as possible the instruments required for their application. Conventional seismic methods generally require tens of geophones together with active seismic sources for monitoring applications. We introduce a method to estimate sea ice properties based on the recordings of seismic noise with only three seismic stations, and demonstrate its potential on data recorded in a frozen fjord in Svalbard, as well as on data collected on drifting sea ice in the Arctic Ocean. The method is shown to have very promising potential for long-term and accurate monitoring of the properties of sea ice.

\section{Introduction}

The propagation of seismic waves guided in sea ice has been exploited for decades to develop methods for the monitoring of the ice properties (Anderson, 1958; Marsan et al, 2012; Moreau et al, 2020; Stein et al, 1998), which are ingredients for climate and sea ice models. These methods exploit the dispersion characteristics of the guided modes that compose the wavefield. With appropriate forward modeling, an inverse problem can be defined to infer the ice thickness and elastic properties, based on a fit between the dispersion of the guided modes in the model and in the data. Such approaches are quite common, not only in geophysics, but also at the ultrasonic scale for nondestructive testing (Mitra and Gopalakrishnan, 2016) or medical acoustics (Bochud et al, 2017) applications. As far as sea ice applications are concerned, the main challenge with such monitoring methods are the in situ logistics, which require the deployment of seismic antennae with many geophones, as well as the use of active sources. Given the hostile conditions and the difficulty to access polar environments, these are considered to be the main limitations of such methods, despite their potential for accurate sea ice properties estimations. Therefore, the long-term monitoring of sea ice with seismic methods remains unlikely as long as autonomous systems with minimal deployment logistics can be used.

Thanks to rapid technological and methodological progress, these constraints are less and less limiting. For example, current technology allows miniature triaxial autonomous geophones to record continuously the seismic wavefield in polar conditions for more than 30 days, at a sampling frequency of $500 \mathrm{~Hz}$. The next generations is expected to record for several months while continuously transmitting the data via satellite communication. Moreover, the need of active sources was recently made unnecessary thanks to analyses based on seismic noise interferometry (Marsan et al, 2012; Marsan et al, 2019; Moreau et al, 2020). 
In Moreau et al (2020), a passive seismic experiment was performed to prove the concept of accurately measuring sea ice thickness and elastic properties with seismic noise. An array of 247 geophones was deployed at the surface of the frozen Van Mijen fjord in Svalbard (Norway), to record the ambient seismic field between 1 and 26 March 2019. The frequencywavenumber dispersion curves of the guided modes propagating in the ice cover were extracted from both icequakes and the noise correlation function (NCF). These dispersion curves were inverted for sea ice thickness, Young's modulus and Poisson's ratio, yielding very accurate and robust estimates when compared with active seismic acquisitions. With this approach, the wavefield must be spatially sampled. This requires a seismic array with stations spacing that meets Nyquist's sampling criterion, with typically $\sim 50$ stations. Although it is expected that about 20-30 stations can be sufficient to apply this technique (Moreau, Lachaud et al, 2017), developing new methods able to achieve similar results with even fewer sensors is desirable to reduce in-situ logistics.

We here introduce a different approach where fewer than 5 stations are sufficient to obtain accurate estimates of sea ice thickness and elastic properties. The method combines noise interferometry for estimating the elastic properties, with a Bayesian inversion of the dispersion in the waveforms of icequakes for inferring ice thickness. It takes advantage of the oneto-one relationship that exists between the time-frequency spectrum of the waveforms on the one hand, and ice thickness and propagation distance on the other hand.

The method is first applied to thin landfast ice. Based on a very rich dataset recorded in 2019 in the Van Mijen fjord, in Svalbard (Moreau et al, 2020), we demonstrate its robustness, stability and accuracy by processing waveforms from many active sources and from icequakes (section 3.1). Then, the method is applied to icequakes recorded on thick pack ice in the Arctic ocean in 2007 (Gascard et al, 2008; Vihma et al, 2014), indicating ice thickness values that are consistent with in situ measurements and field observations (section 3.2).

\section{Material and Methods}

In a layer of ice floating on water, the elastic wavefield contains at least four fundamental guided modes: the quasi-Scholte $(Q S)$, quasi- $S_{0}\left(Q S_{0}\right)$, quasi- $A_{0}\left(Q A_{0}\right)$ and $S H 0$. When the product of the frequency by the thickness of the ice remains under $50 \mathrm{~Hz} \cdot \mathrm{m}$, the $Q A_{0}$ mode is not propagative and the wavefield can be approximated with the combination of the flexural wave, the axial wave, and the shear-horizontal wave (Stein et al, 1998).These are essentially the asymptotic behavior of the guided modes, when the displacement field across the ice thickness is considered linear for the $Q S$ mode and constant for the $Q S_{0}$ mode (Moreau et al, 2020).

For a homogeneous waveguide, modal dispersion depends only on the product between the frequency and the thickness of the waveguide. In particular, for sea ice, the only dispersive mode under $50 \mathrm{~Hz} \cdot \mathrm{m}$ is the $Q S$ mode. The following thickness estimation procedure relies on a time-frequency analysis of this dispersion. More specifically, we minimize the misfit between the dispersion of this mode in recorded and synthetic signals. This inversion procedure is described thereafter.

\subsection{Forward Problem: Phase-Shift-Based Propagation Model}

Given a Young's modulus, $E$, and Poisson's ratio, $v$, the dispersion of the $Q S$ mode is characterized by a time-frequency spectrum which shape corresponds theoretically to a unique combination of ice thickness and propagation distance. A larger propagation distance results in more distorted signals with a dispersion that is specific to the ice thickness. This is illustrated in figure 1 that shows the synthetic waveforms of the $Q S$ at a distance of $80 \mathrm{~m}$ (figure 1a) and $250 \mathrm{~m}$ (figure 1c) from the source, together with their associate short-time Fourier transform (STFT), shown in figures $1 \mathrm{~b}$ and $1 \mathrm{~d}$. Here the source is assumed to produce a 1.5-cycle toneburst with a gaussian shape, and with a centre frequency of $10 \mathrm{~Hz}$, which is representa- 
tive of the dominant frequency observed in most of the icequakes in our data. The ice layer has a thickness $h=0.65 \mathrm{~m}$, Young's modulus $E=4 \mathrm{GPa}$ and Poisson's ratio $v=0.33$, which is representative of the ice near the seismic array in the Van Mijen fjord (Moreau et al, 2020).

To simulate the propagation of the $Q S$ mode, we use a very basic and efficient model which applies, in the Fourier domain, the appropriate phase-shift to each frequency component of the spectrum. This phase-shift depends on the frequency and is equal to $k(f) \times L$, where $k(f)$ is the wavenumber of the $Q S$ mode at frequency $f$ and $L$ is the propagation distance. To compute the wavenumber of the $Q S$ mode, we use the asymptotic low-frequency model introduced by Stein et al (1998), that gives the phase velocity of a time-harmonic flexure wave in an ice layer floating on an infinite water column.

It is noteworthy that sources in the field have complex and varied mechanisms, which have an influence on wave polarization, azimuthal directivity and signals amplitude. This results in signals that are generally quite different from a toneburst. The above-mentioned model by Stein et al (1998) is only for calculating phase velocities, which are not dependent on source mechanisms. Hence, source mechanisms are not accounted for in this model. Moreover, the amplitude information can also be modified along the propagation, for instance if the wave encounters a lead or a ridge. Such field-dependent features cannot be accounted for either, in our basic model. Therefore, in order to mitigate their effect through the inversion procedure, the signal in the model is modified as follows:

1. generate a 1.5-cycle toneburst with a gaussian shape and a center frequency of $10 \mathrm{~Hz}$;

2. Fourier transform this signal;

3. replace the amplitude of the spectrum with that of the signal recorded at the geophone;

4. inverse Fourier-transform the modified spectrum.

This results in a pseudo-impulsive, broadband signal with a spectrum which amplitude is more representative of that from the recorded signal. This signal is then propagated between the source position and the receiver via the above-mentioned phase-shifting operation. In comparison with a non-modified toneburst, the modified propagated waveform will have a reduced misfit with the STFT of the recorded signal.

\subsection{Parameterization of the Problem and Cost Function}

In the following, we assume that $E$ and $v$ can be estimated a priori, and we define a cost function between the data, $\mathbf{d}$, and the output of the model, $\mathbf{m}(\mathbf{X})$, based on the time-frequency analysis of the flexural wave, such that

$$
f(\mathbf{d}, \mathbf{X})=1-\frac{1}{N} \sum_{n=1}^{N} \operatorname{corr}\left(\operatorname{STFT}\left\{\mathbf{d}_{n}\right\}, \operatorname{STFT}\left\{\mathbf{m}_{n}(\mathbf{X})\right\}\right)
$$

where corr denotes the correlation coefficient between matrices $\operatorname{STFT}\left\{\mathbf{d}_{n}\right\}$ and $\operatorname{STFT}\left\{\mathbf{m}_{n}(\mathbf{X})\right\}$. $\mathbf{d}_{n}$ is the temporal signal recorded on the vertical channel at station $n(n=1,2, \ldots, N)$ when an impulsive seismic source is activated, for example an icequake. $\mathbf{m}_{n}(\mathbf{X})$ is the temporal signal simulated at station $n$, based on the input parameters, $\mathbf{X}$. The parameters are representative of the wave propagation problem:

- source latitude

- source longitude

- ice-thickness, $h$

- a time-shifting parameter, $\Delta t$, that accounts for the unknown activation time of the source during the recordings. The aim of this parameter is to "align" the simulated and recorded waveforms. It is the same for all stations. 
a)

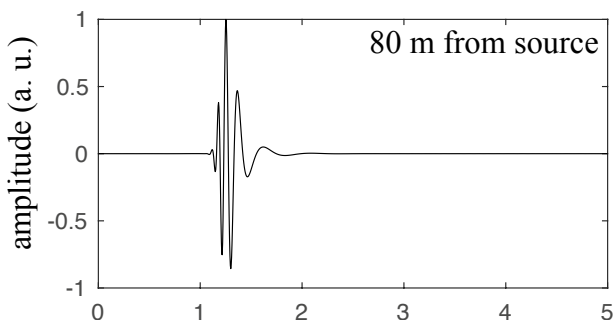

c)

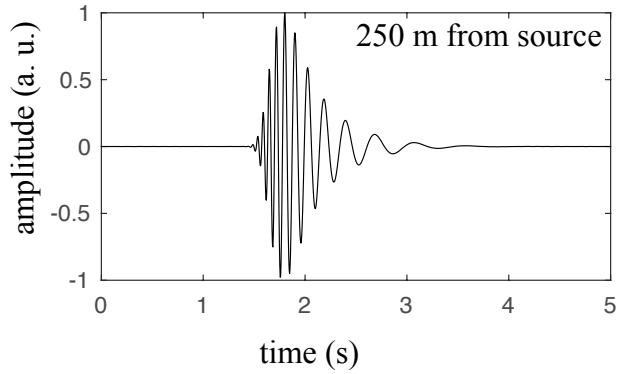

b)

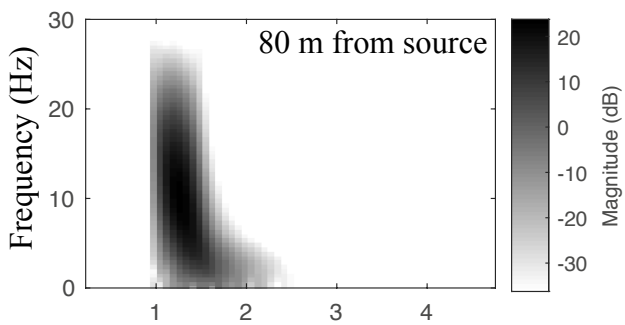

d)

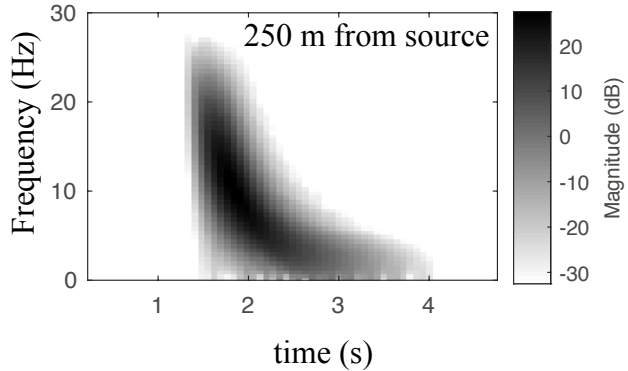

Figure 1. (a) Synthetic waveform of the $Q S$ mode received by a geophone located $80 \mathrm{~m}$ away from an impulsive source in a floating layer of ice with thickness $0.65 \mathrm{~m}$. (b) Short-time Fourier transform of the waveform. (c) and (d): same as (a) and (b) for a geophone located $250 \mathrm{~m}$ away from the source.

This problem is very well-constrained because there is a one-to-one relationship between the model parameters and the global minimum of the cost function. Hence in theory it should be possible to estimate sea ice thickness based on a single signal recorded by a unique seismic station. In practice, however, this can hardly be achieved because the waveforms are corrupted by ice heterogeneity, thickness variations, the presence of a snow layer, anisotropy of elastic properties etc. Nonetheless, the impact of these uncertainties can be mitigated by including data from a few more seismic stations. This significantly improves source localization, which simultaneously also improves thickness estimation. The resulting inferred ice thickness corresponds to an average over all the direct paths between the source and the stations.

\subsection{Inverse Problem}

To solve the inverse problem, we proceed with Bayesian inference, which provides an ensemble of solutions that fit the data with an acceptable level of likelihood, given the data uncertainty. This ensemble of solutions is represented by the posterior distribution of the model parameters, such that

$$
P(\mathbf{X} \mid \mathbf{d})=\frac{P(\mathbf{d} \mid \mathbf{X}) P(\mathbf{X})}{P(\mathbf{d})} .
$$

$P(\mathbf{X} \mid \mathbf{d})$ is the likelihood function, $P(\mathbf{X})$ is the prior distribution and $P(\mathbf{d})$ is the marginal likelihood function, or the model evidence. The posterior distribution expresses the conditional probability of the parameter values based on evidence from measurements, expressed by the likelihood function, and from prior assumptions, expressed by the prior distribution.

The Markov Chain Monte Carlo (MCMC) algorithm is one of several methods that can be used to evaluate the Bayesian posterior distribution by realizing a Markov chain in the parameter search space. This random walk satisfies the ergodic theorem, which allows the algorithm to converge toward a stationary state that approximates the probability density function (PDF) of the parameters (Andrieu and Moulines, 2006). A recurrent problem in Bayesian 
inference is the difficulty to calculate the marginal likelihood, which is essentially a normalization factor. However, because it is the same for all probabilities, its determination is not necessary in practice, since it can be cancelled by comparing ratios of probabilities rather than absolute probabilities. This is one of the motivations for using methods based on stochastic sampling such as MCMC.

In the present problem, it is assumed that measurement errors are uncorrelated and random, and thus that they can be modeled by a normal distribution. A zero-mean Gaussian likelihood function with variance $\sigma^{2}$ is therefore prescribed:

$$
P(\mathbf{d} \mid \mathbf{X})=\exp \left(-\frac{(f(\mathbf{d}, \mathbf{X}))^{2}}{2 \sigma^{2}}\right),
$$

where $\sigma^{2}$ is the variance associated to the measurement errors. This is a typical likelihood function used in many data fitting problems (Tarantola, 2005). Moreover, it is also assumed for the prior distribution that the model parameters have equal probability over a finite range of values:

- the position of sources, which mainly originate from leads, ridges, or the shore line, is within a distance of $2 \mathrm{~km}$ around the centre of the arrays.

- ice-thickness is comprised between $0.1 \mathrm{~m}$ and $5 \mathrm{~m}$.

- the phase-shift adjustment parameter is between $-t_{\max }$ and $+t_{\max }$, where $t_{\max }$ is the size of the time window where the signals to invert are recorded.

MCMC methods generally require a burn-in phase before reaching the posterior distribution. For improved convergence, we precede the MCMC algorithm by a Simulated Annealing (SA) global optimization. The number of iterations is set to 10000 in the SA and to 100000 in the MCMC algorithm. To approximate the PDF of the parameters, we sample 1000 candidates from the posterior distribution of each parameter. Thanks to the ergodic theorem, the mean of the PDF returns the expectation of the parameters, which is also considered here to be the estimated value, because the PDF should be centered around the zone with the highest probability in the parameter space. Another interest of the MCMC algorithm is to provide a confidence in the solution, based on the shape of the PDF.

\section{Results}

\subsection{Landfast Ice in the Van Mijen Fjord in Svalbard}

The data processed in this section were recorded in the Van Mijen fjord near Sveagruva, in Svalbard (Moreau et al, 2020). Figure 2a shows the location of the deployment in the fjord. The array is located near Sveagruva in a part of the fjord that is surrounded by a moraine and connected to the fjord by a channel (figure 2b). The array contains a total of 247 FairFieldNodal Zland geophones (flat frequency response down to the cutoff frequency of $10 \mathrm{~Hz}$ for $1 \mathrm{C}$ instruments and $5 \mathrm{~Hz}$ for $3 \mathrm{C}$ instruments, and an attenuation of $-20 \mathrm{~dB}$ per decade below), as shown in red and blue in figure $2 \mathrm{c}$.

\subsubsection{Elastic Properties of the Ice}

Prior to applying the inversion procedure to the data, the Young's modulus and Poisson's ratio of the ice must be determined. To this end, we evaluate the velocity of the guided $Q S_{0}$ and $S H_{0}$ modes from the noise correlation function (NCF). In passive seismology, the NCF is calculated by correlating the ambient seismic noise (or ambient seismic field) recorded between pairs of stations. It can be shown that it converges toward the impulse response, or Green's function, of the medium (Sabra et al., 2005; Shapiro and Campillo, 2004). As shown in Moreau et al (2020), this approach can be applied to seismic noise recorded on sea ice to recover the Green's function of the wavefield propagating between the stations of a seismic array. 


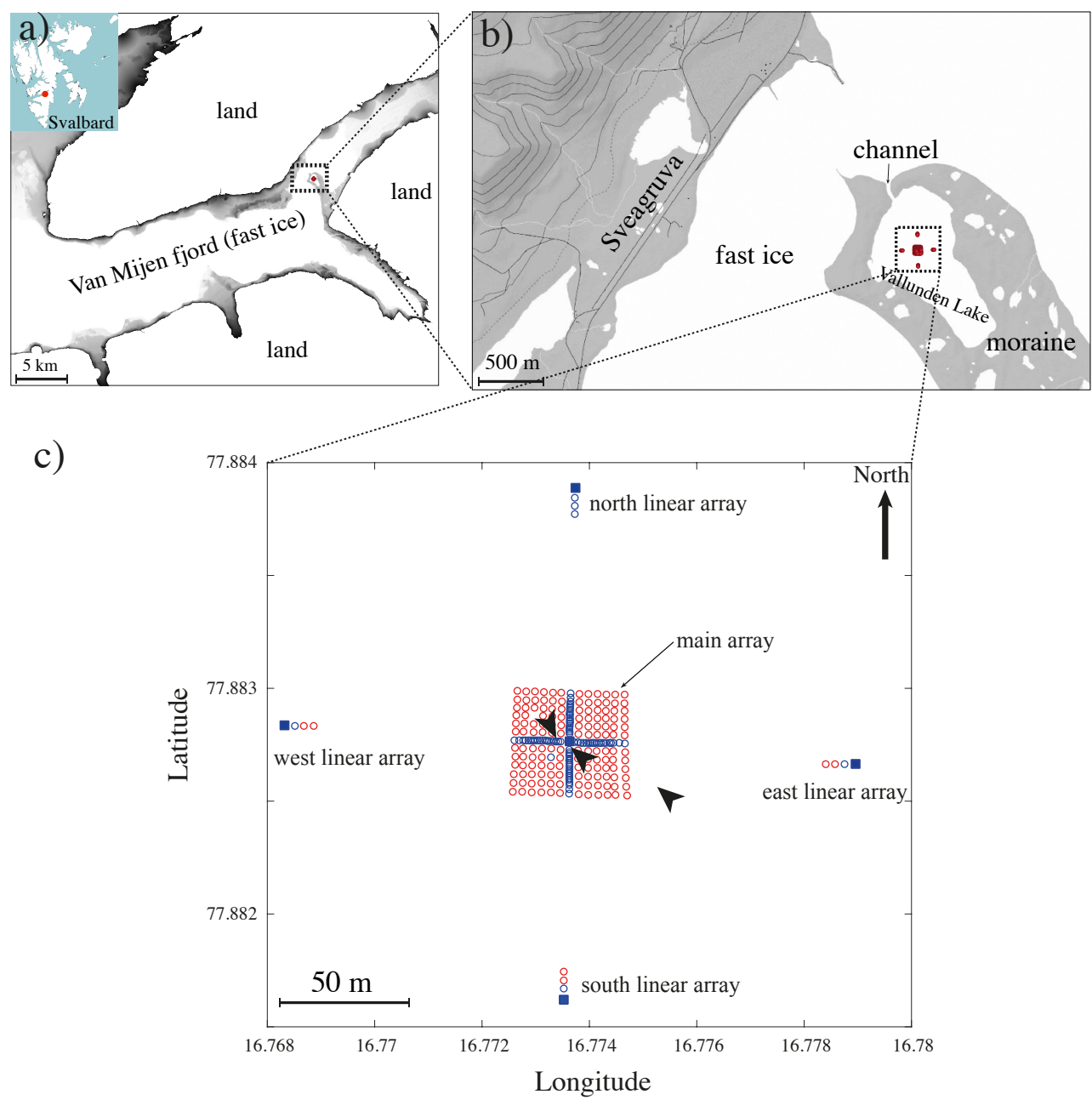

Figure 2. (a) Location of the seismic array in the Van Mijen fjord near Sveagruva (Svalbard), with (b) a zoom around the array area near Vallunden Lake, a part of the fjord that is surrounded by a moraine and connected to the fjord by a channel. The greyscale shows land which altitude is less than $25 \mathrm{~m}$. All land above 25 $\mathrm{m}$ is shown in white to emphasize the shore line. (c) The 247 stations of the array, including the main central array, and the four linear arrays to the north, east, south and west. Red circles are for $1 \mathrm{C}$ stations and blue circles for 3C stations. The 5 blue squares indicate the stations used in section 3.1 to calculate the NCF. The large arrowheads indicate the positions of ice thickness measurements. 


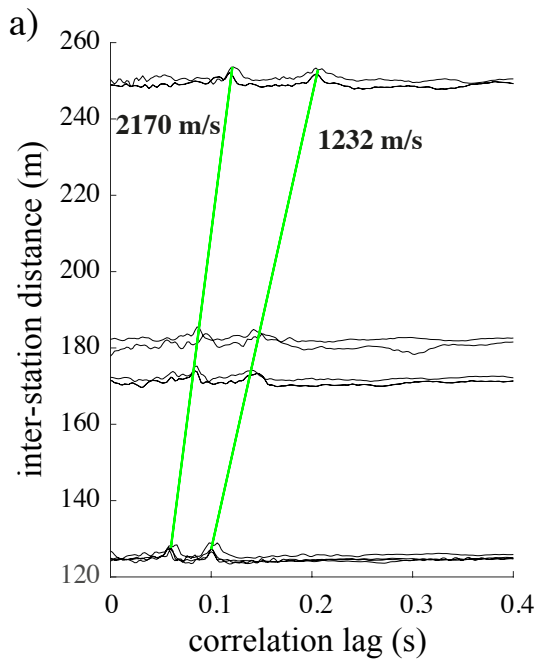

Figure 3. (a) NCF from 8 hrs of seismic noise recorded between $0 \mathrm{~h} 00$ and $8 \mathrm{~h} 00$ on 5 March 2019 in the Van Mijen Fjord, at the stations of the array shown as black squares in figure 2c, versus the distance between the stations. The green lines indicate the arrival time of the $Q S_{0}$ and $S H_{0}$ modes, which propagate at a velocity of $2170 \mathrm{~m} / \mathrm{s}$ and $1232 \mathrm{~m} / \mathrm{s}$, respectively.

When the product of the wavefield by the thickness of the ice remains low, typically up to $200 \mathrm{~Hz} \cdot \mathrm{m}$, the $Q S_{0}$ and $S H_{0}$ modes guided in the ice produce a displacement that is dominant on the horizontal components of the wavefield. Hence we compute the NCF from ambient noise recorded on the horizontal channels of the five geophones shown as squares in figure 2c. The noise was recorded between $0 \mathrm{~h} 00$ and $8 \mathrm{~h} 00$ on 5 March 2019. Recordings were first truncated in $5 \mathrm{mn}$-long time windows and spectral whitening was applied in the [1-20] $\mathrm{Hz}$ frequency band. The cross-correlations were then calculated between each station pair, for all 96 time windows. To obtain the final NCF, the filter introduced in Moreau, Stehly, et al (2017) was applied to each set of cross-correlations, which were finally stacked.

These NCF are shown in figure 3 for the 10 combinations of station pairs as a function of the distance between the stations. They indicate an average velocity of $2170 \mathrm{~m} / \mathrm{s}$ for the $Q S_{0}$ mode and $1235 \mathrm{~m} / \mathrm{s}$ for the $S H_{0}$ mode. These can be related to Young's modulus and Poisson's ratio such that (Stein et al, 1998):

$$
v=1-2\left(\frac{c_{Q S H_{0}}}{c_{Q S_{0}}}\right)^{2}, \quad \text { and } E=\rho \times\left(c_{Q S_{0}}\right)^{2}\left(1-v^{2}\right) .
$$

This gives $E=3.8 \mathrm{GPa}$ and $v=0.35$, which is consistent with the values reported in Moreau et al (2020), $E=3.9 \pm 0.2 \mathrm{GPa}$ and $v=0.34 \pm 0.02$, which were estimated from a frequencywavenumber analysis based on the recordings of 52 geophones. The density is set to $900 \mathrm{~kg} / \mathrm{m}^{3}$, a common value for sea ice. From a rheological point of view, it would be of interest to monitor the evolution of these mechanical properties between 1 and 26 March. Preliminary results indicate that Poisson's ratio keeps a conservative value between 0.32 and 0.33 , and Young's modulus remains stable between 3.8 and $4.5 \mathrm{GPa}$. However this is out of the scope of this paper and is left for separate study.

Next, we apply the inversion method to both active sources (jumps from 1-m height onto the ice), and passive sources (icequakes). The active sources are ideal for a preliminary investigation of the accuracy of the inverted parameters, because they produce signals with a better signal to noise ratio, and also because their exact location is known. We present inversions for these two types of sources, based on signals recorded with 3 and 5 stations. 


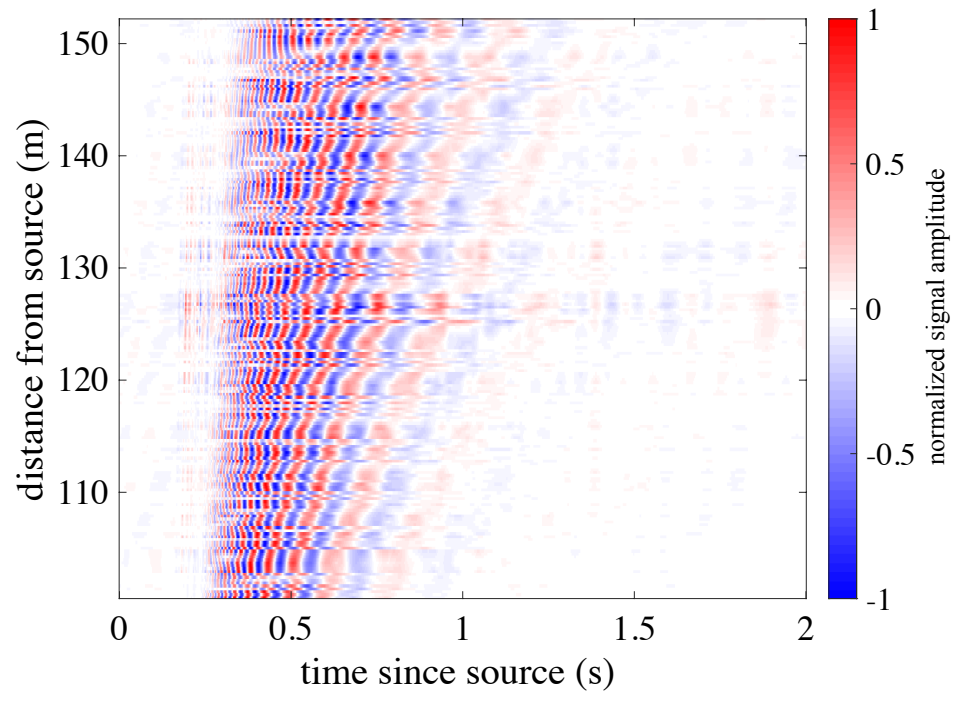

Figure 4. Normalized signals received at all stations of the main array, versus the distance from an impulsive source located in the north linear array. Depending on propagation direction, the moveout of the waveforms is not increasing monotonically, revealing an apparent anisotropy of the wave propagation.

\subsubsection{Inversions of Active Sources For Ice Thickness}

On 1 and 26 March 2019, a series of active acquisitions were performed by jumping directly onto the ice from a one-meter height, near the linear arrays to the north, east, south and west of the main array (figure 2c). In total, 16 jumps were performed on both dates, each at a distance of about $0.5 \mathrm{~m}$ from the geophones in the linear arrays. Signals were extracted from the continuous recordings in a $5 \mathrm{~s}$ time window following the jumps. We refer the reader interested in the exact jumps time to Moreau et al (2020), where they are all listed. The inversion relies on a forward model that is valid when the product of the frequency by the thickness of the ice remains under $50 \mathrm{~Hz} \cdot \mathrm{m}$. Since the ice thickness in the fjord was less than one meter, the extracted signals were band-pass filtered in the [1-50] Hz frequency band.

Although the landfast ice in the fjord is more regular than drifting ice in the open sea, it exhibits significant heterogeneities of mechanical properties through the thickness, as well as local thickness variations by up to $20 \mathrm{~cm}$ Moreau et al (2020). These heterogeneities and thickness variations induce an apparent anisotropy in the propagation of the guided waves. For example, figure 4 shows the waveforms recorded at the main array in the two seconds following a jump at the north linear array. The waveforms are sorted with respect to the increasing distance between the stations and the jump location. The 231 stations of the main array are distributed on a square grid. Hence this sorting implies that from one waveform to the next, the propagation direction can be very different $\left( \pm 15^{\circ}\right)$ while the propagation distance is almost the same. Although the overall moveout exhibits an increasing arrival time, there are also patterns where arrival times are not increasing monotonically, which does not happen when choosing stations that are all in a same line. This is typical of an apparent anisotropy.

\section{- Robustness of the Inversion}

In order to check the robustness of our inversion procedure with regard to these uncertainties, we performed 30 successive inversions of the same source (jump near the northernmost geophone) at two different dates on 1 and 26 March 2019. Each inversion was performed with a different set of geophones that were randomly selected amongst the 247 available. The 
results of the inversions are given in table 1 when using 3 and 5 stations for the inversions. These results show that the method is very robust to the apparent anisotropy, with accurate location of the sources, and thickness estimates with a standard deviation of less than $6.5 \mathrm{~cm}$. It is also noteworthy that when using 3 stations, we identified two cases where the position of the source was less constrained. This occurred in cases where the three stations were close one another (less than $15 \mathrm{~m}$ away), thus creating artificial far field conditions which prevent the azimuthal direction to be constrained. Such configurations were not encountered with 5 stations.

Table 1. Results of the 30 inversions of the active source near the northmost geophone (125 m away from center of main array)

\begin{tabular}{||c|c|c|c|c}
\hline date & 1 March 2019 & 1 March 2019 & 26 March 2019 & 26 March 2019 \\
\hline number of stations for inversion & 5 stations & 3 stations & 5 stations & 3 stations \\
\hline average error on source position & $4.6 \mathrm{~m}$ & $5.2 \mathrm{~m}$ & $6.5 \mathrm{~m}$ & $6.3 \mathrm{~m}$ \\
\hline ice thickness estimation & $50 \pm 3 \mathrm{~cm}$ & $52 \pm 4.5 \mathrm{~cm}$ & $67 \pm 6.5 \mathrm{~cm}$ & $68 \pm 6.6 \mathrm{~cm}$ \\
\hline
\end{tabular}




\section{- Stability of the Inversion}

Next, we also check the stability of the thickness estimations when applied to sources located nearby each other. To this end, once again the four sources at each linear array are used on both dates. Inversions are performed with 3 or 5 stations (figure 5). When using 5 stations, sources to the north, east, south and west are located very accurately, as shown in figure 5a. At both dates, the ice thickness estimates are all within a $4 \mathrm{~cm}$ range for each of the four source areas (figure 5b). When using 3 stations, results have comparable source location accuracies. In terms of ice thickness estimation, the values remain within a range of $6 \mathrm{~cm}$, which is slightly larger than with 5 stations, but still very accurate, especially when considering that part of the variability is most likely due to the direction of propagation, and thus to actual spatial variations of thickness. Overall, the inversion can therefore be considered very stable since estimations from sources located in the same area give very similar values.
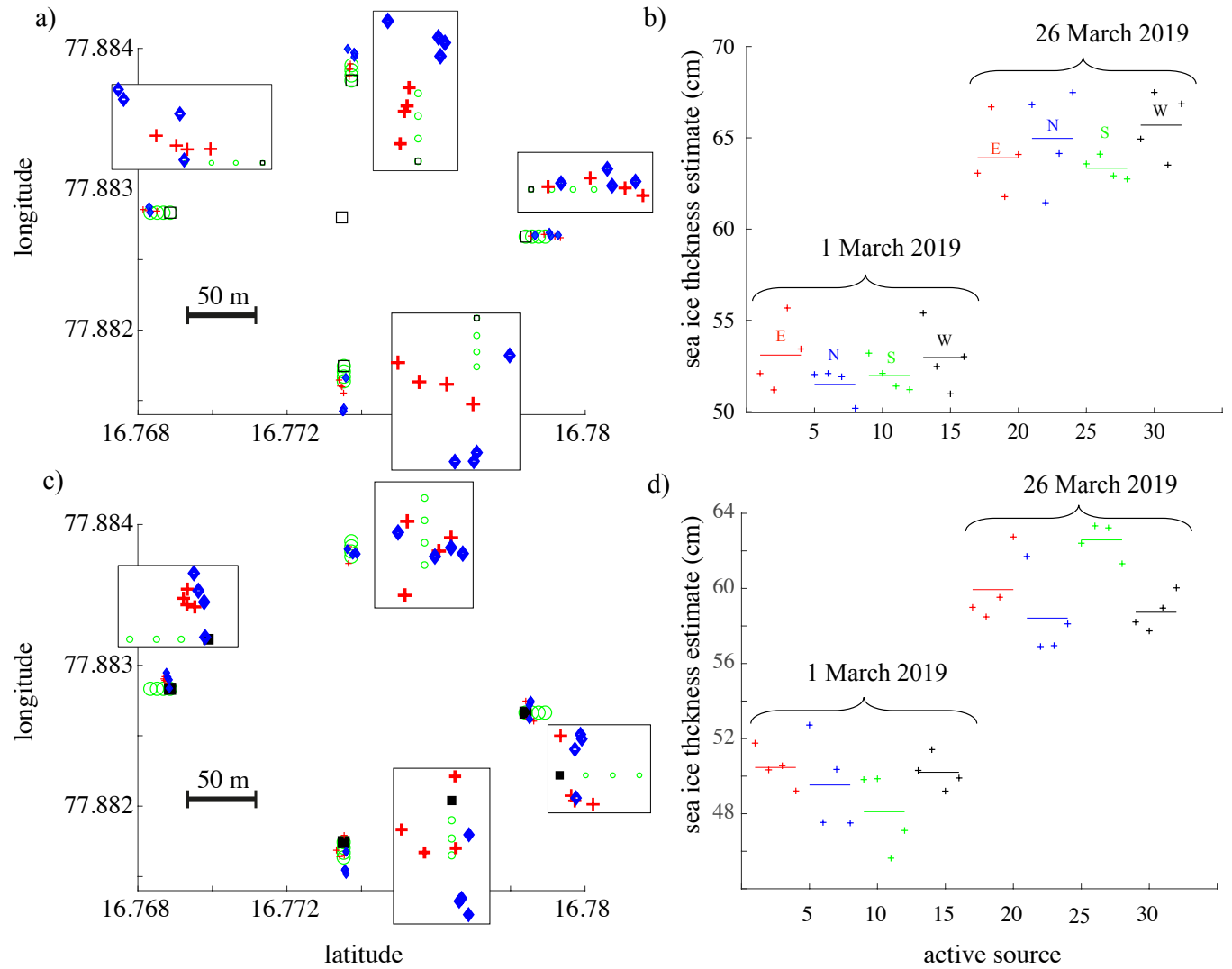

Figure 5. (a) Inverted position of all active sources on 1 March (+) and 26 March ( $\downarrow) 2019$. Green circles represent the sources positions and black squares the stations used for the inversions. The four boxes show a zoom of the localized sources near each linear array. (b) Ice thickness estimates from these inversions. (c) and (d) Same as (a) and (b) with 3 stations only

Note the increase of thickness between March 1 and March 26. This was also observed in the field from ice drillings and ground penetrating radar acquisitions, which indicated an increase of 10-15 cm. Moreover, the thickness estimates are consistent with the values found when applying the method introduced in Moreau et al (2020). This method is based on a simultaneous inversion of the frequency-wavenumber spectrum of the $Q S, Q S_{0}$ and $S H_{0}$ modes. This gave $h=54 \mathrm{~cm}$ with a standard deviation of $3 \mathrm{~cm}$ on 1 March, and $h=74 \mathrm{~cm}$ with a 
standard deviation of $5 \mathrm{~cm}$ on 26 March. The slight differences between the two methods are due to the fact that, on the one hand, the inversion in Moreau et al (2020) averages thickness variations along a short line of 50 stations $(\sim 50 \mathrm{~m})$ via a spatial Fourier transform. On the other hand, the present method averages wave propagation on larger propagation paths $(\sim 250$ $\mathrm{m})$, each with very different directions between the source and the stations.

\subsubsection{Inversions of Icequakes For Ice Thickness}

The main objective is to achieve accurate thickness estimations from passive data only, so that long-term monitoring is made possible without the need of human intervention in the field, other than the deployment of the geophones. Therefore, the method is now applied to icequakes recorded on 5 and 24 March 2019. We attribute these icequakes to the presence of cracks that were observed in the field all along the shore line of the fjord. They are most likely produced by the mechanical stress induced by tidal forcing, and they were either closed or partially open, depending on the tidal phase. The waveforms of these icequakes are shown in figure 6 for three stations, $S_{1}, S_{2}$ and $S_{3}$ (see figure 7), together with the corresponding synthetic waveforms resulting from the inversion with these stations. The average misfit after inversion is of the order of $1 \%$ for both icequakes, indicating that the data can be explained remarkably well with the simple forward model based on 4 parameters only.

The results of the inversions are shown in figure 7, when using 5 stations (figure 7a) or 3 stations (figure 7b), both indicating identical locations of the icequakes. The PDF is slightly more dispersed when only 3 stations are used. This was expected, since the more stations for the inversion, the better constrained the location parameters. The icequake on March 5 is located along the shore to the east of the array, and that on March 24 is located along the shore to the west of the array. This is consistent with the directions found from linear beamforming of the data using all stations of the main seismic array. This beamforming is shown in figures $7 \mathrm{c}$ and $7 \mathrm{~d}$ as slowness of the waveforms versus azimuthal direction. Regarding the thickness, on March 5 the estimated value is $55 \mathrm{~cm}$ with a standard deviation of $2.5 \mathrm{~cm}$ in the PDF when using 5 stations, and $57 \mathrm{~cm}$ with a standard deviation of $3 \mathrm{~cm}$ in the PDF when using 3 stations. On March 24, the estimated thickness is $63 \mathrm{~cm}$ with a standard deviation of $2.7 \mathrm{~cm}$ in the PDF when using 5 stations, and $65 \mathrm{~cm}$ with a standard deviation of $3 \mathrm{~cm}$ in the PDF when using 3 stations. These values are consistent with those found when using active sources, as well as with estimations from the same icequakes when applying the method introduced in Moreau et al (2020), based on an inversion of the wavenumbers of the modes. 
icequake, 24 March 2019

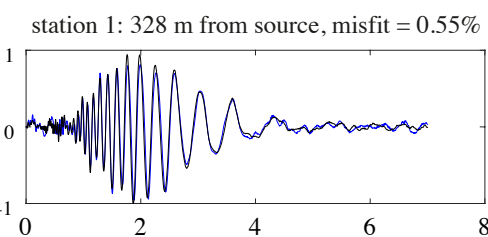

station 2: $216 \mathrm{~m}$ from source, misfit $=0.66 \%$

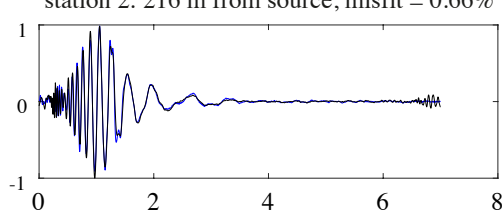

station 3: $439 \mathrm{~m}$ from source, misfit $=2.87 \%$
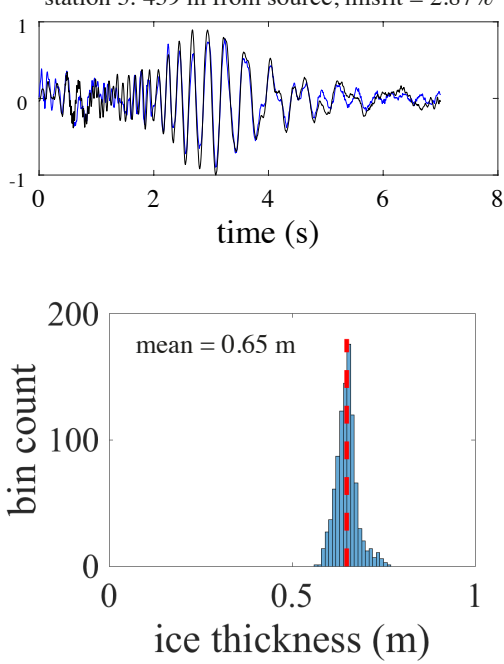

icequake, 5 March 2019

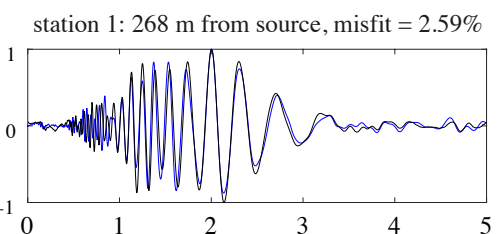

station 2: $362 \mathrm{~m}$ from source, misfit $=1.14 \%$
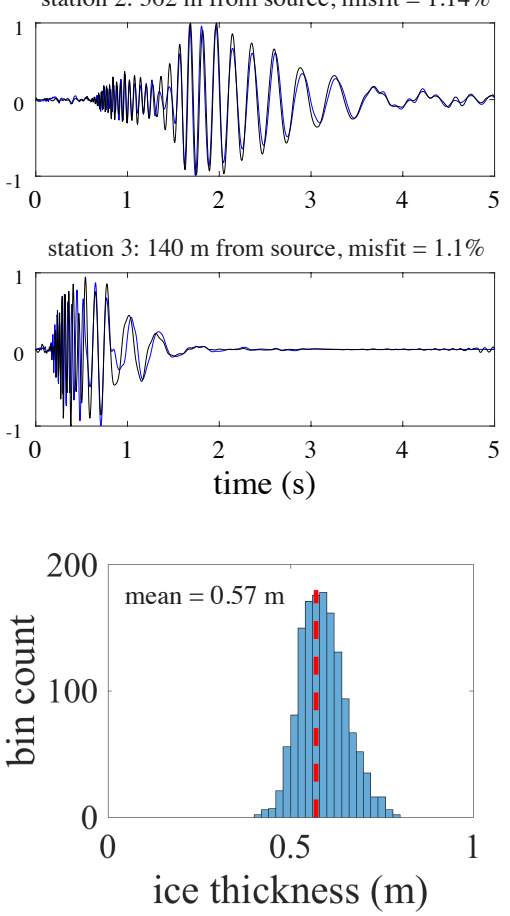

Figure 6. Top: waveforms of the icequakes recorded in the Van Mijen fjord (black) and the corresponding synthetic waveforms (blue), resulting from the inversion with 3 stations $\left(S_{1}, S_{2}\right.$ and $S_{3}$ : see figure 7). Bottom: PDF of the ice thickness, with the mean value shown as dashed line. 
a)

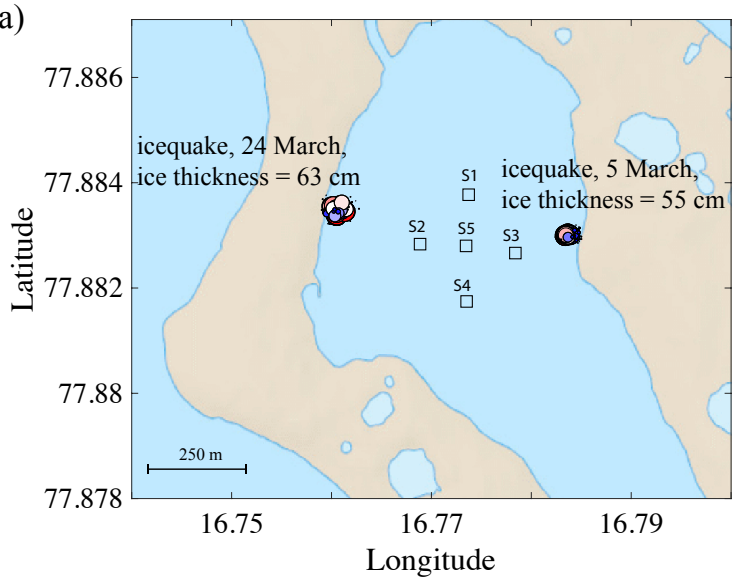

c)

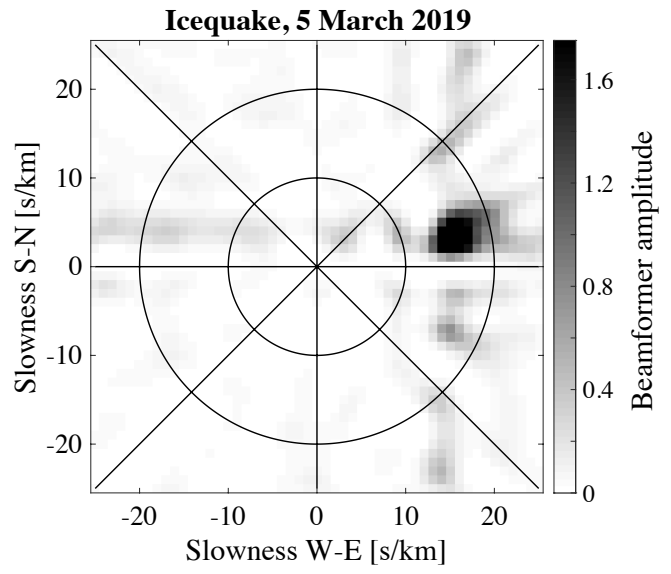

b)

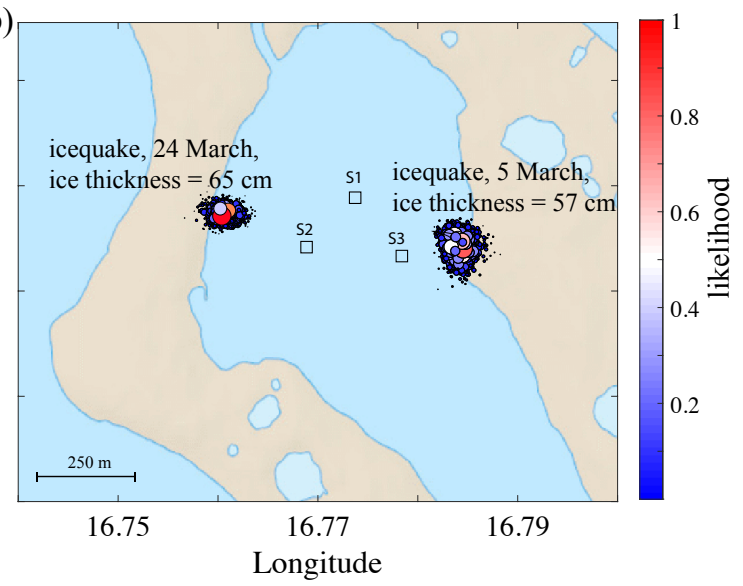

d)

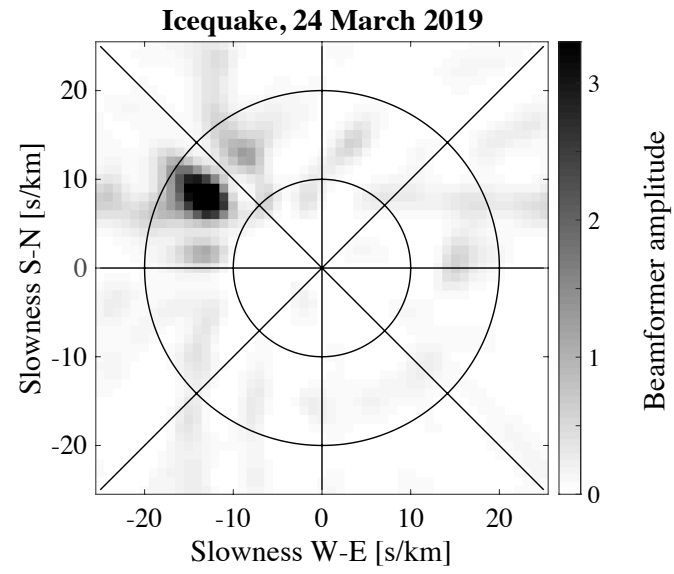

Figure 7. Top: Map showing the result of inversions for icequakes recorded at the Van Mijen fjord. The diameter and color of the circles are proportional to the likelihood in the posterior distribution of the parameters. The squares indicate the stations used for the inversions. Inversion of the icequakes was performed with (a) 5 stations and (b) 3 stations. Stations are labelled $\mathrm{S}_{i}, i=1,2, \ldots 5$. Bottom: Slowness vs azimuth linear beamforming of the icequakes recorded on 5 March (c) and 24 March (d). The beamforming was computed in the $7-9 \mathrm{~Hz}$ frequency band, using the 231 stations of the main array. Some slight aliasing is visible. 


\subsection{Pack ice within the Arctic ocean}

The seismic data analyzed in this section were already described in Marsan et al (2011): a seismic network was deployed in April 2007 as part of the measurement campaign at the Tara drifting station operating in the framework of the DAMOCLES (Developing Arctic Modeling and Observing Capabilities for Long-term Environmental Studies) project (Gascard et al, 2008). Figure 8a shows a part of this network made of four seismic antennae labelled Tromso, Paris, Tartu and Helsinki. Each antenna contains four short-period $(1 \mathrm{~Hz})$ vertical seismometers and one broadband Güralp CMG-3ESPC seismometers, installed in a diamond-shaped geometry with the triaxial seismometer in the centre. Figure $8 \mathrm{~b}$ shows an approximate map of the situation in the field, with many leads around the four antennae, as well as the ice drilling and electromagnetic sounding positions relative to the antennae. The corresponding thickness profile between antennae Tromso and Tartu are shown in figure 8c, together with an histogram of thickness values (figure $8 \mathrm{~d}$ ), which indicates that the average thickness of the level ice is about $2 \mathrm{~m}$.

For our analyses, we use one hour of continuous recordings on 1 May 2007 between 0:00 and 1:00, at antenna Helsinki (figures $8 \mathrm{a}$ and $8 \mathrm{~b}$ ). One of these recordings is shown in figure 9a, with a zoom between 0:30:30 and 0:36:00 (figure 9b) and the corresponding spectrogram

a)

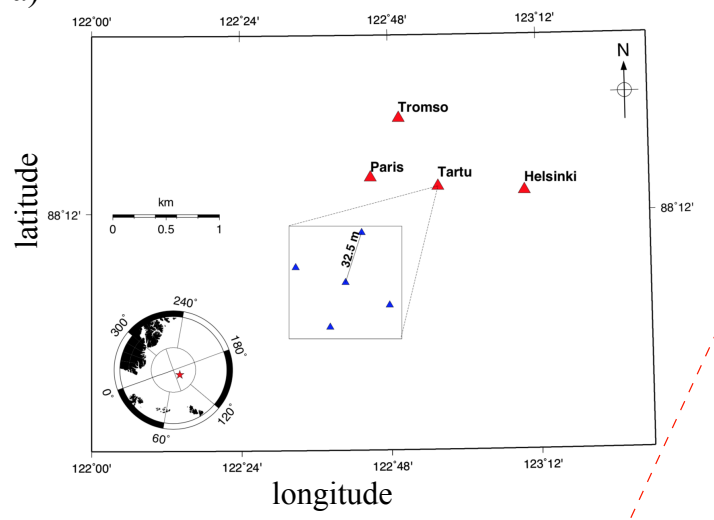

c)

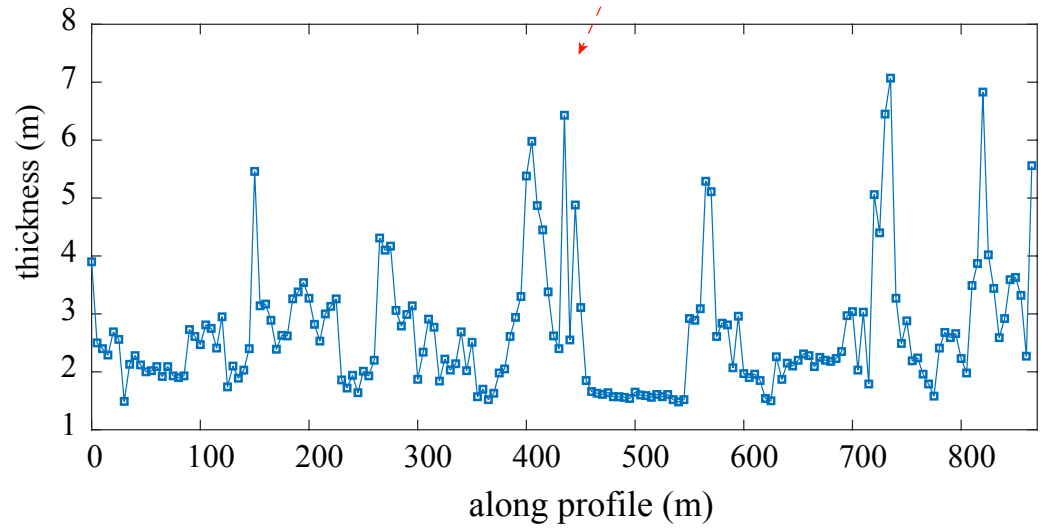

b)

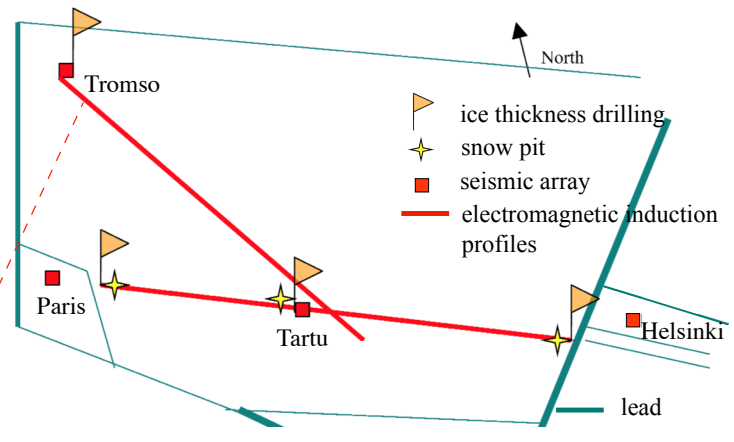

d)

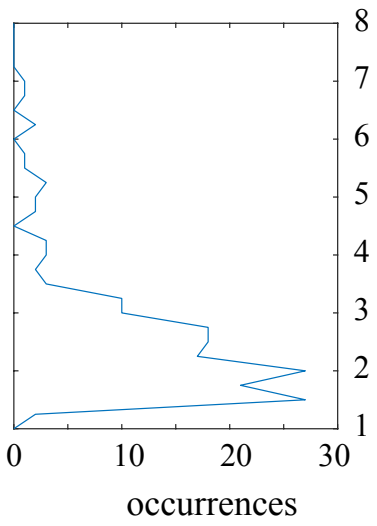

Figure 8. (a) Sketch of four the seismic antennae Tromso, Paris, Tartu and Helsinki, installed at the Tara ice station. The inset shows the geometry of one array, with typical inter-sensor distance. (b) Approximate map showing the situation in the field, with the position of the antennae relative to the leads, as reported by the Tara's onboard crew. (c) Ice thickness profile from drilled holes and electromagnetic induction between stations Tromso and Tartu. (d) Histogram of the thickness values. 
(figure 9c). Hundreds of icequakes with energy up to $25 \mathrm{~Hz}$ are visible. In order to satisfy the validity criterion of the forward model, signals are low-pass filtered under $10 \mathrm{~Hz}$. This allows thicknesses up to $\sim 5 \mathrm{~m}$ to be tested while keeping frequency-thickness values under the upper limit of $50 \mathrm{~Hz} \cdot \mathrm{m}$.

\subsubsection{Elastic Properties of the Ice}

Because only one station of the Helsinki antenna is a $3 \mathrm{C}$ instrument, the method used in section 3.1 to evaluate Young's modulus and Poisson's ratio from noise interferometry is not possible here. We tried to exploit the horizontal channels of this station by including, in the cost function, the arrival times of the $Q S_{0}$ and $S H_{0}$ modes. This would allow the velocity of the modes to be evaluated, based on the propagation time and the distance from the source, which could be used in turn for a joint inversion of ice thickness and elastic properties. However, this approach was not conclusive due to poor SNR in the data, which prevented the arrival times of these modes to be picked accurately. A potential solution consists in looking for icequakes originating from identical sources (also known as repeaters), via template matching methods. Stacking those waveforms could help tackle the SNR issue. However, the goal here is to demonstrate the potential of the inversion method when applied to a dataset acquired with the appropriate instruments, and there is no doubt that the elastic properties of the ice could be determined from the NCF, for example if the same geophones as those used on landfast ice had been used too. Hence, such ad hoc solutions are not investigated further here, since they are out of the scope of this paper.

For thick pack ice, reports in the literature give Young's moduli that vary between 6.1 $\mathrm{GPa}$ and 8.6 GPa, while values for Poisson's ratio are more conservative around $v=0.33$ (Hunkins, 1960; Stein et al, 1998). In absence of in situ evaluations of the elastic properties, we use $E=7.2 \mathrm{GPa}$ and $v=0.33$, following the recommendation in Marsan et al (2012), and the density is set to $900 \mathrm{~kg} / \mathrm{m}^{3}$. Of course, choosing a different value of Young's modulus would change the value of the inferred ice thickness. However, this change would not be significant because the ice thickness parameter is much more constrained by the curvature of the STFT than it is by Young's modulus. Nonetheless, further investigations are required to quantitatively evaluate this sensitivity. This is left for a separate study, as this represents a considerable amount of inversions and analyses that are out of the scope of this paper.

\subsubsection{Inversion of Icequakes For Ice Thickness}

The vast majority of the recorded icequakes are not resolved in time, as shown in figure $9 \mathrm{~b}$, where one can see that the waveforms are partly superposed. This prevents a clear dispersion to be extracted from the time-frequency spectrum (figure 9c). The waveforms are also much noisier than those recorded in the Van Mijen fjord. We suggest that this is due to i) instrumentation issues, because SNR varies significantly between the stations, and to ii) a noisier environment, as shown in figure 9c where a low-frequency seismic noise with energy between 0.5 and $3 \mathrm{~Hz}$ is always present. Unfortunately, this is a frequency band where part of the useful dispersion information is present as well. This reduces the amount of icequakes suitable for an inversion to less than $1 \%$. Yet, this should not be considered a fundamental problem, given the thousands of icequakes that trigger every day. Moreover, the thickness profile shown in figure $8 \mathrm{c}$ indicates significant local variations between $1.6 \mathrm{~m}$ and $7 \mathrm{~m}$, due to deformed ice and pressure ridges (Haas et al, 2011). Such large variations likely modify the seismic wave propagation and cause scattering. With all the above-mentioned difficulties, this dataset represents the main challenge for our proof of concept.

To select icequakes suitable for an inversion, the following heuristic criteria were used:

1. the waveforms are clearly resolved in time and well-separated from those of other icequakes. 


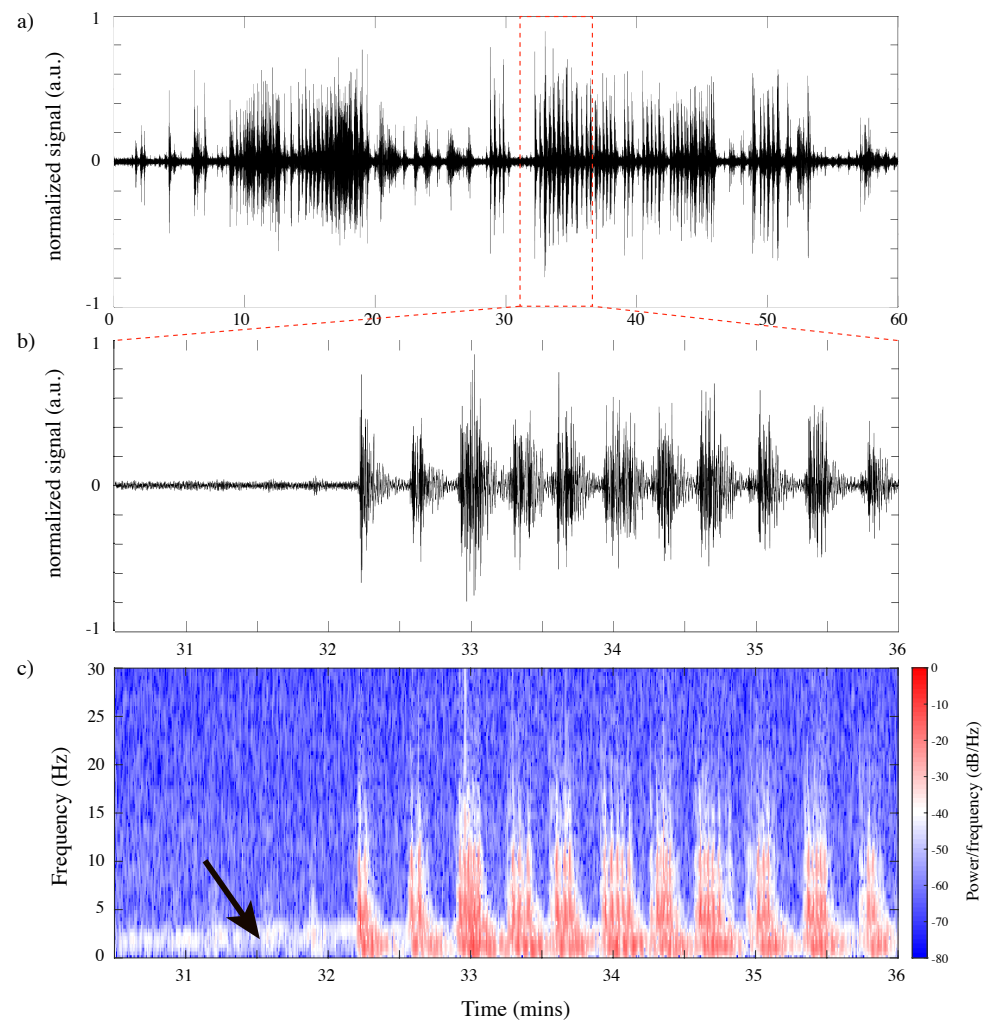

Figure 9. (a) One hour of seismic recording at one station of the HELSINKI antenna. (b) Zoom between 0:30:30 and 0:36:00 and (c) the corresponding short-time Fourier transform. The black arrow indicates a systematic seismic noise with energy between 0.5 and $3 \mathrm{~Hz}$. 
2. the SNR in the time-frequency spectrum allows the dispersion to be quantified between 0.5 and $20 \mathrm{~Hz}$.

Based on these criteria, three icequakes were selected. The waveforms of two of these icequakes are shown in figure 10, together with the corresponding synthetic waveforms resulting from the inversion with 5 stations. The average misfit after inversion is of the order of 5\% to $10 \%$. This indicates that the data can be explained reasonably well with the forward model. Figure 11 shows the corresponding inversions, performed with 5 stations (figure 11a) and less (figure 11b). The posterior distributions are shown in terms of the icequakes position relative to the array. They all indicate that the icequakes originate from the main lead located to the west of the array. With 5 stations, the estimated thickness was:

- $2.02 \mathrm{~m}$ for the icequake recorded at 0:02:06 with a standard deviation of $33 \mathrm{~cm}$ in the PDF;

- $2.06 \mathrm{~m}$ for the icequake recorded at 0:02:19 with a standard deviation of $32 \mathrm{~cm}$ in the PDF;

- $2.04 \mathrm{~m}$ for the icequake recorded at 0:28:47 with a standard deviation of $35 \mathrm{~cm}$ in the PDF. Note the non-gaussian shape of the PDF. This suggests a local minimum, in the cost function, that is associated to a thickness with relatively high likelihood around 2.5 $\mathrm{m}$.

And with less than 5 stations:

- the inversion for the icequake recorded at 0:02:06 was not conclusive;

- $2.08 \mathrm{~m}$ for the icequake recorded at 0:02:19 with a standard deviation of $37 \mathrm{~cm}$ in the PDF, with 4 stations;

- $2.03 \mathrm{~m}$ for the icequake recorded at 0:28:47 with a standard deviation of $39 \mathrm{~cm}$ in the PDF, with 3 stations, although the icequake was not located exactly at the same position as when using 5 stations. Moreover, the PDF of the position parameters exhibits a wider spread. This is most likely a consequence of poor SNR combined with fewer stations used for the inversion.

In absence of thickness measurements around the array, we cannot give a definitive answer regarding the accuracy of these estimates. However, they are consistent with the measurements shown in figures $9 \mathrm{~b} 9 \mathrm{c}$ which indicate an average thickness of $\sim 2 \mathrm{~m}$ for the level ice, west of the main lead. These results are very encouraging, since we demonstrate that, despite poor SNR and significant local thickness variations that scatter wave propagation, icequakes can be located and ice thickness inferred with very good confidence. The standard deviation in the PDF are of the order of $30 \mathrm{~cm}$, which indicates that the confidence in the solution is not as good as for the estimations from the previous dataset. This is a consequence of the larger misfit value $(\sim 5-10 \%$ instead of $\sim 1 \%)$. We are confident that this misfit could be reduced by i) using instruments of the latest generation (for example those used on landfast ice), and ii) using a forward model able to account for the local variations in ice properties, such as a finite element model, but at the cost of significantly increased computational resources. However, we suggest that the actual standard deviation of the ice thickness estimation is much less than that in the PDF, since all inferred values remain within a $6 \mathrm{~cm}$ margin. 


\section{icequake, 0:02:06}
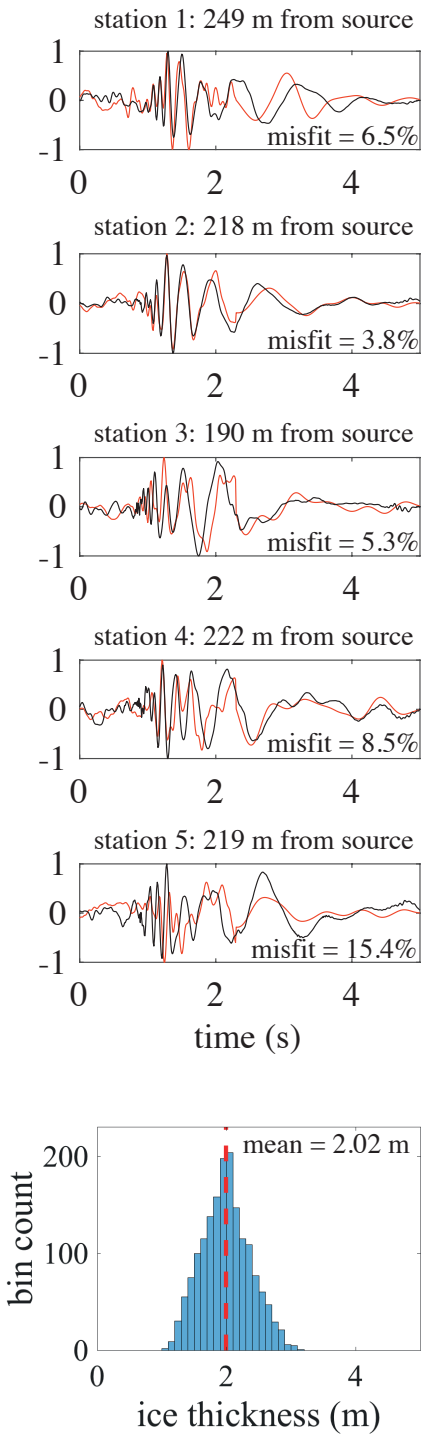

icequake, 0:02:19

station 1: $129 \mathrm{~m}$ from source

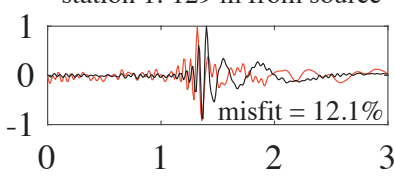

station 2: $135 \mathrm{~m}$ from source

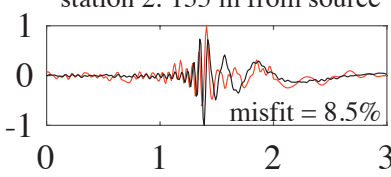

station 3: $100 \mathrm{~m}$ from source
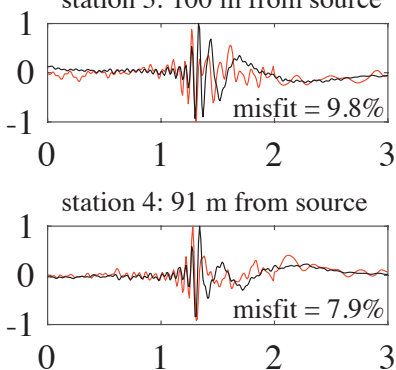

station 5: $111 \mathrm{~m}$ from source
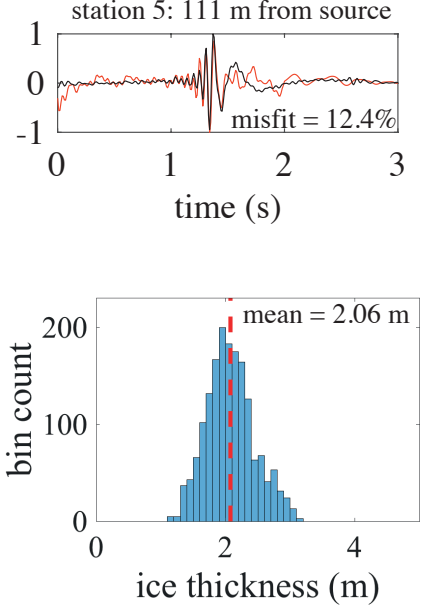

icequake, $0: 28: 47$

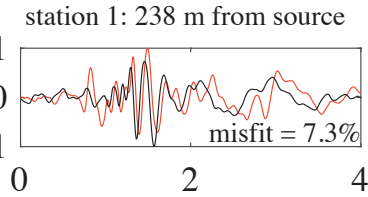

station 2: $212 \mathrm{~m}$ from source

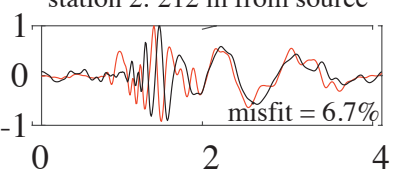

$1 \underbrace{1}_{0}$ station 3: $180 \mathrm{~m}$ from source
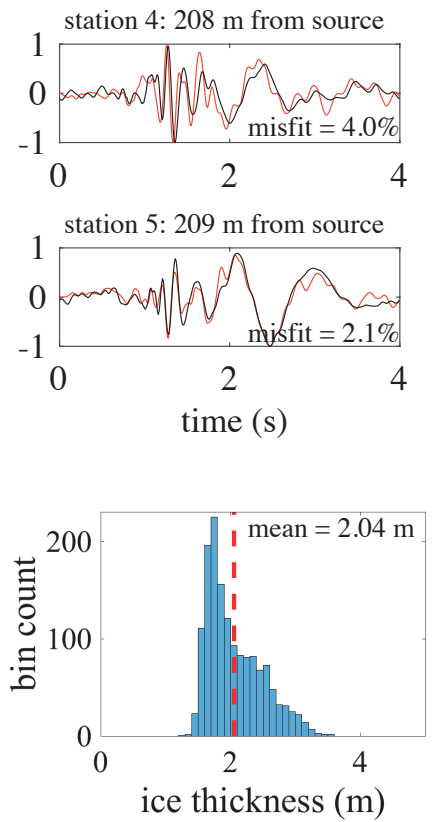

Figure 10. Top: Waveforms of the icequakes recorded on pack ice (black) and the corresponding synthetic waveforms (red), resulting from the inversion with 5 stations. Bottom: PDF of the ice thickness, with the mean value shown as dashed line. 

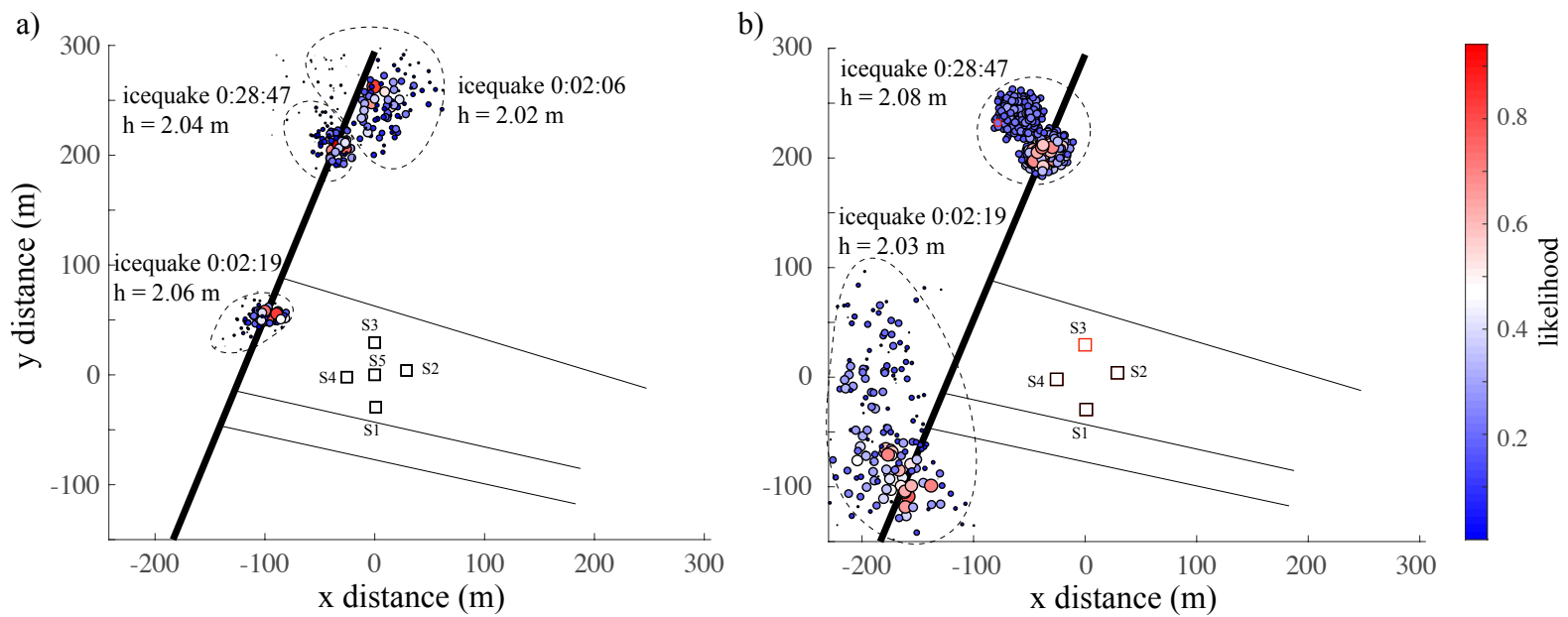

Figure 11. Map showing the result of inversions for icequakes recorded on drifting sea ice at the Helsinki antenna. The diameter and color of the circles are proportional to the likelihood in the posterior distribution of the parameters. The squares indicate the stations used for the inversions. Solid lines show the approximative position of the leads relative to the stations. (a) Inversion of three icequakes with 5 stations. (b) Inversion of the icequake at i) 0:02:19 with 3 stations (black squares), and ii) 0:28:47 with 4 stations (black and red squares). The black dashed curves delimit the PDF of the icequakes position. The dashed curves separate the PDF of icequakes position.

\section{Concluding Remarks}

A method was introduced to estimate the elastic properties of sea ice from seismic noise interferometry, as well as the ice thickness from the time-frequency dispersion of the flexural wave. This approach only requires passive recordings of seismic noise on 3 to 5 triaxial seismic stations (depending on SNR), to provide accurate and robust estimations of sea ice properties, while simultaneously relocating the icequakes. In thin landfast ice, we found an ice thickness between $\sim 55 \mathrm{~cm}$ at the beginning of March and $\sim 65 \mathrm{~cm}$ at the end of March, with a standard deviation less than $5 \mathrm{~cm}$ in the posterior distribution of the thickness parameter. In thick pack ice, we found an ice thickness of $\sim 2.05 \mathrm{~m}$ and a standard deviation of $\sim 30 \mathrm{~cm}$ in the PDF, but the values found from all inversions remain within a $6 \mathrm{~cm}$ interval, which suggests that the actual standard deviation is significantly less. All thickness estimations are consistent with measures made directly in the field (ice drillings, electromagnetic induction, ground penetrating radar).

Our investigations indicate that the proposed monitoring procedure exhibits similar performances when using 3 or 5 geophones, as long as the SNR allows a clear dispersion to be extracted from the waveforms of the icequakes. For example, thickness estimations remain within a $2 \mathrm{~cm}$ range in both cases. Of course, in configurations where 5 geophones are used instead of 3 , the icequake location is better constrained, and consequently so is the ice thickness. However, the accuracy of the inferred parameters is comparable. Moreover, from the 60 array configurations tested in section 3.1.2, it appears that different array geometries lead to similar results, so long as the stations in the array are not all near one another. In data where SNR is poorer and the extraction of the dispersion is more difficult, using 3 geophones may not always be sufficient for a successful inversion. Hence for optimal monitoring results, we prescribe the deployment of arrays of 4 to 5 geophones per $1 \mathrm{~km}^{2}$ areas, where the stations configuration is such that it maximizes spatial coverage. 
Despite the demonstrated accuracy and robustness of our approach, reducing the misfit between synthetic and field data is essential to reduce the uncertainty in the solution. For this reason, future works should focus on two main directions. The first one is the improvement of SNR, for example via the automatic selection and denoising of icequake waveforms for optimal results. To this end, machine learning-based approaches such as clustering or template matching, have proved very promising. The second one is the use of efficient forward models able to account for local variations of ice properties while keeping the computational cost to an acceptable level.

Our estimations of the ice thickness correspond to an average over the propagation paths between the icequake origin and the seismic stations. It is therefore expected to be applicable at all scales of icequake propagation, that is, any distance up to a few kilometers in the frequency range of the present study. However, an interesting perspective of this work is the study of remote rupture sources, potentially hundreds of kilometers away, by investigating wave propagation at much lower frequency with stations spaced by $\sim 100 \mathrm{~km}$. Most of what is known about sea ice deformation and fracturing comes from large-scale $(>10 \mathrm{~km})$ satellite observations, such as the RGPS (RADARSAT Geophysical Processor System) dataset (Kwok, 1998) or from the analysis of Lagrangian trajectories (buoys) (Rampal et al, 2008). Satellite imagery allows to highlight that large scale deformation is mostly accommodated at the scale of a few days by linear structures of large dimensions (up to the scale of the basin). These structures are likely to be brittle (Marsan et al, 2004). The temporal resolution of how the rupture occurs along such long structures is still lacking, but could be analyzed by exploiting similar methods as exposed here.

The use of icequakes presents the advantage of being a completely passive approach, without the need of active sources. Given the very large number recorded every hour ( $>500$ both in pack ice and landfast ice), one can fairly expect them to originate from a large range of directions and distances around the stations. This would open the way towards exhaustive, timedependent thickness tomographies of the ice, similar to the velocity tomographies of the crust. Moreover, the exploitation of the horizontal channels may pave the way towards simultaneous inversions of the ice thickness and elastic properties, potentially with only two stations. This can be achieved by including, in the cost function, the waveforms of the other two fundamental modes $\left(\mathrm{SH}_{0}\right.$ and $\left.Q S_{0}\right)$.

A complementary perspective of this work is to apply the present method to the noise correlation function instead of icequakes. As shown in Moreau et al (2020), the correlation of seismic noise recorded at two stations for a few hours quickly converges towards the impulse response of sea ice between these stations. Since the relative position of the stations is known from GPS coordinates, the source-receiver station distance would be perfectly constrained, allowing for an even more accurate inversion of the ice thickness. The noise correlation function also integrates the contribution of all seismic sources, impulsive or more stationary. It naturally results in more energetic waveforms than those from icequakes, which has potential to extend the scales at which ice thickness can be inferred. 


\section{Acknowledgments}

The metadata of the dataset recorded in Svalbard are available at the following doi: http:// dx. doi.org/10.15778/RESIF. XG2019. The full dataset (total size $=3.2 \mathrm{~Tb}$ ) is available upon request to the corresponding author. A subset can be accessed instantly via a direct download link (25 Gb in size for each day). To request this link, please send an e-mail to resif -dc@ujf-grenoble.fr with your affiliation and IP address. This subset contains the continuous recordings of all stations on 1 and 5 March 2019, from which part of the results presented in this paper were obtained (with $3 \mathrm{C}$ stations data downsampled at $500 \mathrm{~Hz}$ ). The dataset recorded on pack ice in the Arctic Ocean (a few $\mathrm{Mb}$ in size) is available upon request to the corresponding author.

ISTerre is part of Labex OSUG@2020. This research was funded by the Agence Nationale de la Recherche (ANR, France), and by the Institut Polaire Français Paul-Emile Victor (IPEV).

The authors would like to thank the associate editor and reviewers for the useful and constructive comments.

\section{References}

Anderson, D. L. (1958), Preliminary results and review of sea ice elasticity and related studies, Trans. Eng. Inst. Canada 2:116-122

Andrieu, C. and E. Moulines (2006) On the ergodicity properties of some adaptative MCMC algorithms, The Annals of Applied Probability 16(3), 1462-1505, doi: $10.1214 / 105051606000000286$

Bochud, N, Q. Vallet, J.G. Minonzio and P. Laugier (2017), Predicting bone strength with ultrasonic guided waves, Sci Rep 7, 43628, doi: 10.1038/srep43628

Gascard, J.-C, H. le Goff, M. Weber, B. Bruemmer, M. Offermann, M. Doble, P. Wadhams, R. Forsberg, S. Hanson, H. Skourup, S. Gerland, M. Nicolaus, J.-P. Metaxian, J. Grangeon, J. Haapala, E. Rinne, C. Haas, A. Wegener, G. Heygster, E. Jakobson, T. Palo, J. Wilkinson, L. Kaleschke, K. Claffey, B. Elder and J. Bottenheim (2008), Exploring Arctic transpolar drift during dramatic sea ice retreat, Eos, 89(3): 21-23, doi: 10.1029/2008EO030001

Hass, C., H. Le Goff, S. Audrain, D. Perovich and J. Haapala (2011), Comparison of seasonal sea-ice thickness change in the Transpolar Drift observed by local icemass balance observations and floe-scale EM surveys, Ann. Glac. 52:97-102, doi: $10.3189 / 172756411795931778$

Hunkins, K. (1960), Seismic studies of sea ice, J. Geophys. Res. 65(10):3459-3472, doi: 10.1029/JZ065i010p03459.

Kwok, R., (1998) The RADARSAT Geophysical Processor System. In: Analysis of SAR Data of the Polar Oceans, Springer, Berlin, Heidelberg: 235-257, doi: 10.1007/978-3642-60282-5_11

Marsan, D., H. Stern, R. Lindsay and J. Weiss (2004), Scale Dependence and Localization of the Deformation of Arctic Sea Ice, $\quad$ Phys. Rev. Lett. 93(17): 178501, doi: 10.1103/PhysRevLett.93.178501

Marsan, D., J. Weiss, J.-P. Métaxian, J. Grangeon, P.-F. Roux and J. Haapala (2011) Low frequency bursts of horizontally-polarized waves in the Arctic sea-ice cover, J. Glaciol. 57(202): 231-237, doi: 10.3189/002214311796405834

Marsan, D., J. Weiss, E. Larose, and J.-P. Métaxian (2012) Sea-ice thickness measurement based on the dispersion of ice swell, J. Acoust. Soc. Am., 131(1):80-91, doi: $10.1121 / 1.3662051$

Marsan, D., J. Weiss, L. Moreau, F. Gimbert, M. Doble, E. Larose and J. Grangeon (2019), Characterizing horizontally-polarized shear and infragravity vibrational modes in the Arctic sea ice cover using correlation methods, J. Acoust. Soc. Am., 145(3):16001608, doi: $10.1121 / 1.5094343$ 
Mitra, M. and S. Gopalakrishnan (2016) Guided wave based structural health monitoring: A review Smart Mater. Struc., 14(5):0964-1726, doi: 10.1088/0964-1726/25/5/053001

Moreau, L., C. Lachaud, R. Théry, M. V. Predoi, D. Marsan, J. Weiss and M. Montagnat (2017), Monitoring ice thickness and elastic properties from the measurement of leaky guided waves: A laboratory experiment J. Acoust. Soc. Am., 142(5):2873-2880, doi: $10.1121 / 1.5009933$

Moreau, L., L. Stehly, P. Boué, Y. Lu, E. Larose, and M. Campillo (2017-b), Improving ambient noise correlation functions with an svd-based Wiener filter, Geophys. J. Int., 211(1):418-426, doi: 10.1093/gji/ggx306

Moreau, L., P. Boué, A. Serripierri, J. Weiss, D. Hollis, I. Pondaven, B. Vial, S. Garambois, E. Larose, A. Helmstetter, L. Stehly, G. Hillers, and O. Gilbert (2020), $\quad$ Sea ice thickness and elastic properties from the analysis of multimodal guided wave propagation measured with a passive seismic array, J. Geophys. Res-Oceans, 125(4):e2019JC015709, doi: 10.1029/2019JC015709

Rampal, P., J. Weiss, D. Marsan, R. Lindsay and H. Stern (2008), Scaling properties of sea ice deformation from buoy dispersion analyses, J. Geophys. Res., 113: C03002, doi: 10.1029/2007JC004143.

Sabra, K.G., P. Gerstoft, P. Roux, W.A. Kuperman and M.C. Fehler (2005), Extracting timedomain Green's function estimates from ambient seismic noise, Geophys. Res. Lett 32, 79-84, doi:10.1029/2004GL021862

Shapiro, N. M. and M. Campillo (2004), Emergence of broadband Rayleigh waves from correlations of the ambient seismic noise, Geophys. Res. Lett., 31:L07614 doi:10.1029/2004GL019491

Stein, P. J., S. E. Euerle, , and J. C. Parinella (1998), Inversion of pack ice elastic wave data to obtain ice physical properties, J. Geophys. Res. 103(C10):21783-21796

Tarantola, A. (2005), Inverse Problem Theory and Methods for Model Parameter Estimation, Society for Industrial and Applied Mathematics, Philadelphia, Pennsylvania.

Vihma, T., R. Pirazzini, I. Fer, I. A. Renfrew, J. Sedlar, M. Tjernström, C. Lüpkes, T. Nygård, D. Notz, J. Weiss, D. Marsan, B. Cheng, G. Birnbaum, S. Gerland, D. Chechin, and J. C. Gascard (2014) Advances in understanding and parameterization of small-scale physical processes in the marine Arctic climate system: a review, Atmos. Chem. Phys. 14: 9403-9450, doi: 10.5194/acp-14-9403-2014 